\title{
Effect of concentration of the diazoalcene molybdenum complex immobilized in ureasil matrix
}

\author{
N. Nunes, F. Costa, A.M. Fonseca, C.J.R. Silva, I.C. Neves* \\ Departamento de Química, Universidade do Minho, Campus de Gualtar, 4710-057 \\ Braga, Portugal. E-mail: *ineves@quimica.uminho.pt
}

\begin{abstract}
The complex trans-[FMo(NNCHCHCHCH$\left.\left.{ }_{2} \mathrm{CH}_{3}\right)\left(\mathrm{Ph}_{2} \mathrm{PCH}_{2} \mathrm{CH}_{2} \mathrm{PPh}_{2}\right)_{2}\right]\left[\mathrm{BPh}_{4}\right]$, was dispersed in a hybrid matrix synthesized by a sol-gel process. The host matrix of the so-called ureasil is a network of silica to which oligopolyoxyethylene chains [POE, $\left.\left(\mathrm{OCH}_{2} \mathrm{CH}_{2}\right)_{\mathrm{n}}\right]$ are grafted by means of urea cross-links. The free complex and sol-gel materials were characterized by thermal analysis (DSC), surface analysis (XPS) and spectroscopic methods (FT-IR and UV/Vis). The data gathered indicates that the molybdenum(IV) complex is immobilized in the host matrix, and it exhibits structural properties different from those of the free form. These differences could arise either from distortions caused by steric effects imposed by the structure of hybrid matrix or by interactions with the matrix. These materials shows potential applications in heterogeneous catalysis in mild conditions.
\end{abstract}

\section{Introduction}

A major challenge in the research of catalysis is the immobilization of organometallic complexes into solid supports such as zeolites and other porousstructured materials like hybrid organic-inorganic materials produced by the sol-gel process [1-2]. These new materials used the host-guest concept, obtained by sol-gel process, combining the homogeneous catalytic properties of metal complexes with some characteristics of the heterogeneous catalysts, such as shape selectivity and/or separation from reaction media. For example, the pore size of the gel can be controlled by sol-gel process [3-4]. 
We have been interested in the heterogenisation of metal complexes in Pillared Clay (PILC) [5] and zeolites [6] and have shown that the methodologies used for encapsulation/immobilization of the metal complexes are largely determined by the properties of the supporting phase. The analogy between microporous solid and hybrid matrix materials obtained by sol-gel promotes us to explore the properties of the former as support for the immobilization of metal complexes.

In this paper, we describe the effect of the concentration upon the molybdenum complex (scheme 1) dispersed into a high molecular weight ureasil structure, U(600), which contains about 8.5 oxyethylene repeating units. The macromolecular structure is composed by oligopolyoxyethylene chains grafted onto a siliceous network through urea bridges [-NHC( $=\mathrm{O}) \mathrm{NH}-][7-8]$.

\section{Insert scheme 1}

\section{Experimental}

\section{Preparation of host matrix containing the complex}

In the first stage of material synthesis, the host matrix was prepared by reaction of a doubly functional amine, $\mathrm{O}, \mathrm{O}^{\prime}$-bis(2-aminopropyl)-polyethylene glycol-500, (Jeffamine ED-600 ${ }^{\circledR}$, Fluka), with 3-isocyanatepropyltriethoxysilane (ICPTES, Aldrich), in tetrahydrofuran (THF), to give ureapropyltriethoxysilane (ureasil - UPTES) [7]. Finally, a measured volume of metal complex solution $\left(5 \times 10^{-3} \mathrm{~mol} / \mathrm{dm}^{3}\right)$ in THF, was incorporated in the UPTES solution. The immobilization of the metal complex is achieved simultaneously by hydrolysis and condensation reactions. Details of the preparation of the synthesis ureasil precursor (UPTES) with metal complex can be found in authors' previous work [9].

The ureasil samples have been identified by the nomenclature $\mathrm{U}(600)_{n}[\mathrm{MoL}]\left[\mathrm{BPh}_{4}\right]$ where $\mathrm{U}(600)$ represents the pure matrix, where ' $\mathrm{U}$ " comes from "ureasil" and 600 indicate the average molecular weight of diamine used. The $n$ represents the molecular ratio between the Jeffamine (the limiting reagent used in the ureasil synthesis) and the metal complex. Samples with $n=100(4.4 \mu \mathrm{mol}$ of metal complex $), 500(0.88 \mu \mathrm{mol}$ of metal complex $)$ and $1000(0.44 \mu \mathrm{mol}$ of metal complex $)$ were prepared. The $[\mathrm{MoL}]\left[\mathrm{BPh}_{4}\right]$ nomenclature for the metal complex is denominated $\underline{\mathrm{Mo}}=\mathrm{FMo}\left(\mathrm{Ph}_{2} \mathrm{PCH}_{2} \mathrm{CH}_{2} \mathrm{PPh}_{2}\right)_{2}$ were $\mathrm{L}$ is the diazoalcene ligand, 
$\left(\mathrm{NNCHCHCHCH}_{2} \mathrm{CH}_{3}\right)$. The obtained material was a flexible, non-rigid, brittle and homogeneous transparent film with brown coloration.

Preparation of $\mathrm{Mo}(\mathrm{IV})$ complex

The complex trans-[MoF( $\left(\mathrm{NNH}_{2}\right)\left(\mathrm{dppe}_{2}\right]\left[\mathrm{BF}_{4}\right]$ was prepared by a methodology described in literature [10]. This complex $(0.45 \mathrm{~g}, 0.44 \mathrm{mmol})$ was dissolved in THF $(20 \mathrm{~mL})$ at room temperature, and trans-2-pentenal $(146 \mu \mathrm{L}, 1.5 \mathrm{mmol})$ was added to the solution. After $6 \mathrm{~h}$, the resulting brown solution was filtered and hexane $(4 \mathrm{~mL})$ was added to the filtrate to give brown-green crystals, which were filtered off, washed with ether and hexane, and then dried in vacuo. The product was dissolved in methanol (20 $\mathrm{mL}$ ) and an excess of $\mathrm{NaBPh}_{4}$ was added to the stirred solution. Brown trans$\left[\mathrm{MoF}\left(\mathrm{NNCHCHCHCH} \mathrm{CH}_{3}\right)(\mathrm{dppe})_{2}\right]\left[\mathrm{BPh}_{4}\right]$ precipitated. This was filtered off, washed with methanol $(3 \times 5 \mathrm{~mL})$, ether $(3 \times 5 \mathrm{~mL})$ and recrystallized with $\mathrm{CH}_{2} \mathrm{Cl}_{2} / \mathrm{Et}_{2} \mathrm{O}$ and dried in vacuo. Yield (0.43 g, $73 \%$ ) Anal. Found for $\mathrm{MoFC}_{81} \mathrm{H}_{76} \mathrm{~N}_{2} \mathrm{P}_{4} \mathrm{~B}$ (calcd.): $\mathrm{C}$, 73.6 (73.3); H, 5.6 (5.7); N, 2.1 (2.1). NMR $\left(\mathrm{CDCl}_{3}\right):{ }^{1} \mathrm{H}(300.0 \mathrm{MHz}) ; \delta=0.8(\mathrm{t}, 3 \mathrm{H}$, $\left.\mathrm{C}_{3}\right), 1.3\left(\mathrm{~m}, 2 \mathrm{H}, \underline{\mathrm{C}}_{2} \mathrm{CH}_{3}\right), 2.6-2.8\left(2 \mathrm{~m}, 8 \mathrm{H}, \mathrm{PC}_{2} \underline{\mathrm{C}}_{2} \mathrm{P}\right), 5.2(\mathrm{t}, 1 \mathrm{H}, \mathrm{NC} \underline{\mathrm{HCH}}), 6.0$ (m, 2H, olefinic protons) and 7.0-7.6 (m, 60H, $\mathrm{PPh}_{2}$ and $\left.\mathrm{BPh}_{4}\right) .{ }^{31} \mathrm{P}-\left\{{ }^{1} \mathrm{H}\right\}(121.7 \mathrm{MHz})$, $\delta$-98.5 (s). FTIR $\left(v / \mathrm{cm}^{-1}\right): 1572[v(\mathrm{C}=\mathrm{N})], 1313[v(\mathrm{C}=\mathrm{C})] . \mathrm{UV} / \mathrm{Vis}\left(\lambda_{\max } / \mathrm{nm}\right): 320$ and 510.

\section{Characterization}

The IR spectra of free complex and ureasil samples were obtained from powdered samples on $\mathrm{KBr}$ pellets, using a Bomem MB104 spectrometer in the range 4000-500 $\mathrm{cm}^{-1}$ by averaging 20 scans at a maximum resolution of $4 \mathrm{~cm}^{-1}$. Film samples were sealed in a $20 \mu \mathrm{L}$ aluminum pan inside a preparative glovebox under argon atmosphere. Thermal analysis was carried out with a Mettler TC11 controller and a DSC20 Mettler oven under high purity argon supplied at a constant $50 \mathrm{~mL} \mathrm{~min}{ }^{-1}$ flow rate. All samples were subjected to a $10{ }^{\circ} \mathrm{C} \mathrm{min}-1$ heating rate and were characterized between 25 and 350 ${ }^{\circ} \mathrm{C}$. X-ray photoelectron spectroscopy was performed on a VG Scientific ESCALAB 250iXL spectrometer using an Alka monochromatized radiation (1486.92 eV). Reflectance UV/vis spectra of free complex and sol-gel materials were obtained from solid sample films and were recorded on a Shimadzu UV/2501PC spectrophotometer at room temperature in the range $800-200 \mathrm{~nm}$. 


\section{Results and Discussion}

Vibrational spectroscopy can provide information both about the immobilized complex and host matrix. The infrared spectra of ureasil samples and the free complex in the spectral region of $2000-550 \mathrm{~cm}^{-1}$ are shown in Figure 1. The spectra of all samples are dominated by bands due to the host matrix U(600). The IR spectrum of hosted matrix has been previously characterized [11-12].

\section{Insert Figure 1}

As the complex is much diluted in host matrix, the bands due to the complex are much weaker and can only be observed in the region between 1050 and $800-550 \mathrm{~cm}^{-1}$, where the $\mathrm{U}(600)$ does not absorb. The spectrum of the free complex is dominated by the characteristic bands of diphenylphosphine ligands (1484, 1435, 742 and $691 \mathrm{~cm}^{-1}$ ) and the $\mathrm{BPh}_{4}{ }^{-}$anion $\left(1052,744\right.$ and $720 \mathrm{~cm}^{-1}$ ) [13]. The bands recorded at $1572 \mathrm{~cm}^{-1}$ and $1313 \mathrm{~cm}^{-1}$ are assigned to the $v(\mathrm{C}=\mathrm{N})$ and $v(\mathrm{C}=\mathrm{C})$ groups of diazoalcene ligand. The IR bands of immobilized $[\underline{\mathrm{MoL}}]\left[\mathrm{BPh}_{4}\right]$ in the range $1050-550 \mathrm{~cm}^{-1}$, are assigned to the diphenylphosphine ligands and $\mathrm{BPh}_{4}{ }^{-}$anion. They occur at frequencies which are shifted by $10 \mathrm{~cm}^{-1}$ from those shown by the free complex. These results indicate primarily that the complex has been immobilized in the $U(600)$ and the shift observed in the bands can be attributed to the distortion of the complex induced by the structure or by interactions with host matrix.

To understand the effect of molybdenum complex concentration on thermal properties of the host matrix, studies using differential scanning calorimetry (DSC) were performed. The DSC thermograms shown in figure 2 substantiate that all samples are totally amorphous.

\section{Insert Figure 2}

The DSC thermograms obtained for pure matrix and samples with immobilized metal complex shows high thermal stability, confirming the expected mechanical and thermal properties for this material. However, we observed that at low metal complex concentration the endothermic processes is assigned to solvent evaporation $\left(60-120{ }^{\circ} \mathrm{C}\right)$ and they are more intense than those recorded for the pure matrix. At higher concentrations the same thermal processes are less intense. This behavior suggests that the presence of the metal complex contributes to matrix stabilization and this is 
probably due to the increase of localized chemical interactions between atoms from the $[\underline{\mathrm{MoL}}]\left[\mathrm{BPh}_{4}\right]$ and those from the matrix structure.

The XPS resolution spectrum of ureasil samples showed the presence of carbon, oxygen, nitrogen, boron, fluorine, silicon as well as chlorine (figure 3).

\section{Insert Figure 3}

With the exception of chlorine, all other elements are expected for ureasil structure and metal complex. The traces of chlorine come from the solvent used during the purification process of metal complex. The XPS analysis detected the presence of the molybdenum in the sol-gel materials. The low Mo contents at surface levels observed indicate that the outermost surface is not enriched in Mo. The metal complex is immobilized into the ureasil structure. The fluorine and boron present in metal complex composition are observed in samples with higher $[\mathrm{MoL}]\left[\mathrm{BPh}_{4}\right]$ concentrations.

Figure 4 shows the electronic spectra of $U(600)$ and metal complex immobilized in host matrix.

\section{Insert Figure 4}

The electronic spectrum of $\mathrm{U}(600)$ is very similar to those observed in materials with similar matrices [12]. The ureasil samples exhibits in 250-300 nm range several intense bands at $\lambda_{\max }=255,265$ and $272 \mathrm{~nm}$. These bands occur in the same range as the high-energy charge-transfer band $\left(\lambda_{\max }=320 \mathrm{~nm}\right)$ observed for $[\underline{\mathrm{MoL}}]\left[\mathrm{BPh}_{4}\right]$, which does not allow direct evidence for the immobilization of the metal complex in host matrix. However, the shift observed does provide evidence for the existence of intermolecular interactions between metal complex and matrix. The same behaviour is observed with a higher concentration of metal complex.

\section{Conclusion}

The combination of all techniques used on this study made it possible to conclude that the molybdenum complex was immobilized in host matrix produced by sol-gel. The obtained transparent and amorphous monoliths materials were found to show good mechanical properties. Their excellent optical transparency was maintained over a large range of $[\mathrm{MoL}]\left[\mathrm{BPh}_{4}\right]$ concentration. Furthermore, the analysis of the obtained data suggests that the structure exhibits a framework topology similar to that of the ureasil 
structure. However, there is evidence of host-guest interaction between the molybdenum complex and the matrix, which contributes to increase the cohesion and order of the resulting material. This study opens a new window of application of these materials as a support matrix for active homogeneous catalysts.

\section{Acknowledgments}

Dr. Carmen Serra Rodrigues (C.A.C.T.I., Vigo University, Spain) is gratefully acknowledged for performing and analyzing the XPS measurements.

\section{References}

[1] L. Canali and D.C. Sherrington, Chem. Soc. Rev., 28, 85 (1999).

[2] D. Pini, A. Mandoli, S. Orlandi and P. Salvadori, Tetrahedron: Asymmetry 10, 3883 (1999).

[3] C.J. Brinker and G.W. Scherer, Sol-Gel Science: The Physics and Chemistry of SolGel Processing (Academic Press, San Diego, 1990) p. 40.

[4] D.R. Rolison and B. Dumn, J. Mater. Chem. 11, 963 (2001).

[5] F. Costa, C.J.R. Silva, M. Raposo, A.M. Fonseca, I.C. Neves, A. P. Carvalho and J. Pires, Micropor. Mesopor. Mat., submitted for publication

[6] I. Neves, C. Freire, A.N. Zakharov, B. Castro and J.L. Figueiredo, Colloids Surf. A. Physicochem. Eng. Aspects 115, 249 (1996).

[7] M. Armand, C. Poinsignon, J.Y. Sanchez and V.Z. Bermudez, U.S. Pat., 1994, $5,283,310$.

[8] V.Z. Bermudez, L.D. Carlos, M.C. Duarte, M.M. Silva, C.J.R. Silva, M.J. Smith, M. Assunção and L. Alcácer, J. of Alloys and Compounds, 275, 21(1998).

[9] I. Montinho, V. Boev, A. M. Fonseca, C. J. R. Silva and I. C. Neves, Solid State Sciences, 5, 203 (2003).

[10] Y. Ishii, H. Miyagi, S. Jitsukuni, H. Seino, B.S. Harkness and M. Hidai, J. Am. Chem. Soc., 114, 9890 (1992)

[11] M.M. Silva, V.Z. Bermudez, L.D. Carlos, A.P.P. Almeida and M.J. Smith, J. Mater. Chem. 9, 1735 (1999).

[12] C. Marques, A. M. Sousa, C. Freire, I. C. Neves, A. M. Fonseca and C. J. R. Silva, J. Alloys Compd. 306 (2003) 272. 
[13] Y. Mizobe, Y. Uchida and M. Hidai, Bull. Chem. Soc. Jpn., 53, 1781 (1980). 
Keywords: Molybdenum(IV) complex; Diazoalcene; Sol-gel; Complex immobilization; Host-guest 


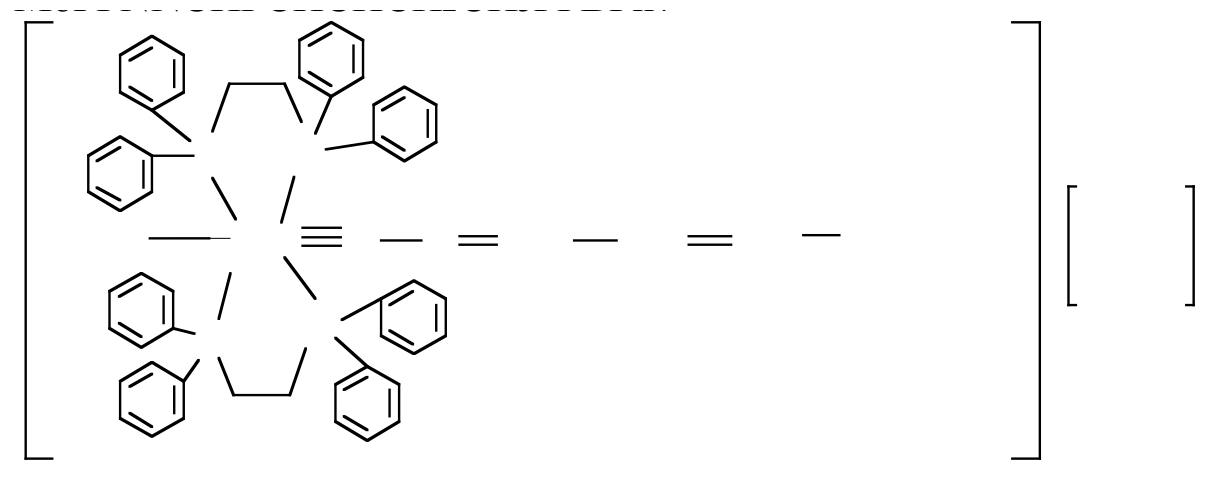

Scheme 1 


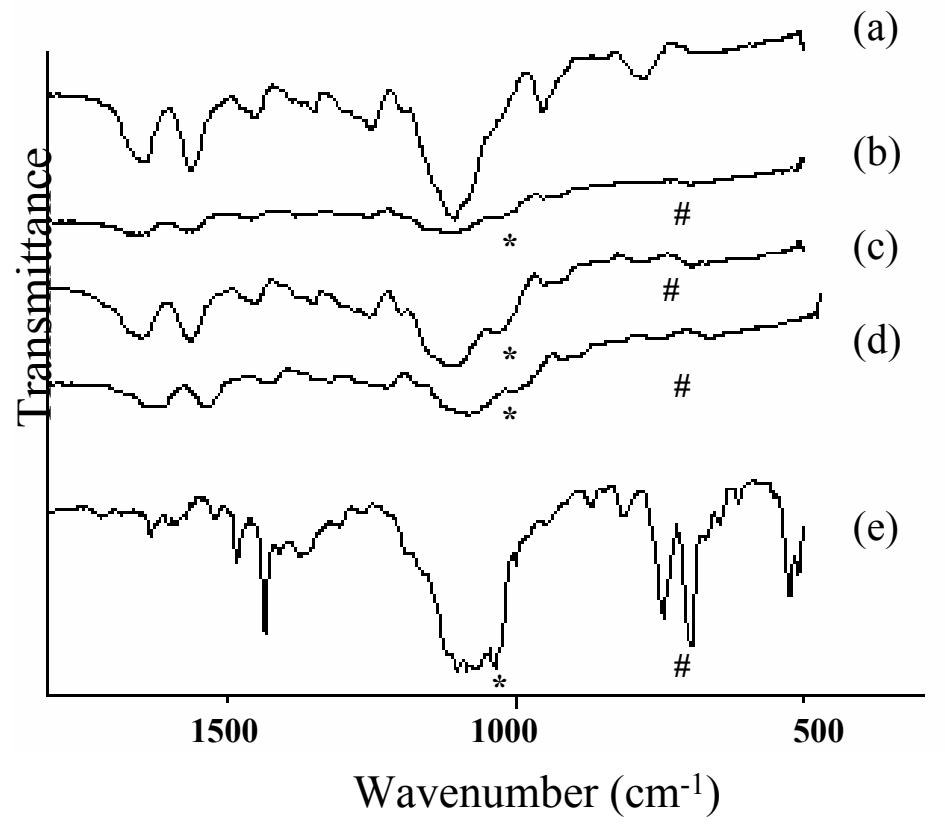

Figure 1 - FTIR spectra: (a) U(600), (b) $\mathrm{n}=100$, (c) $\mathrm{n}=500$ (d) $\mathrm{n}=1000$ and (e) $[\underline{\mathrm{MoL}}]\left[\mathrm{BPh}_{4}\right]$. 


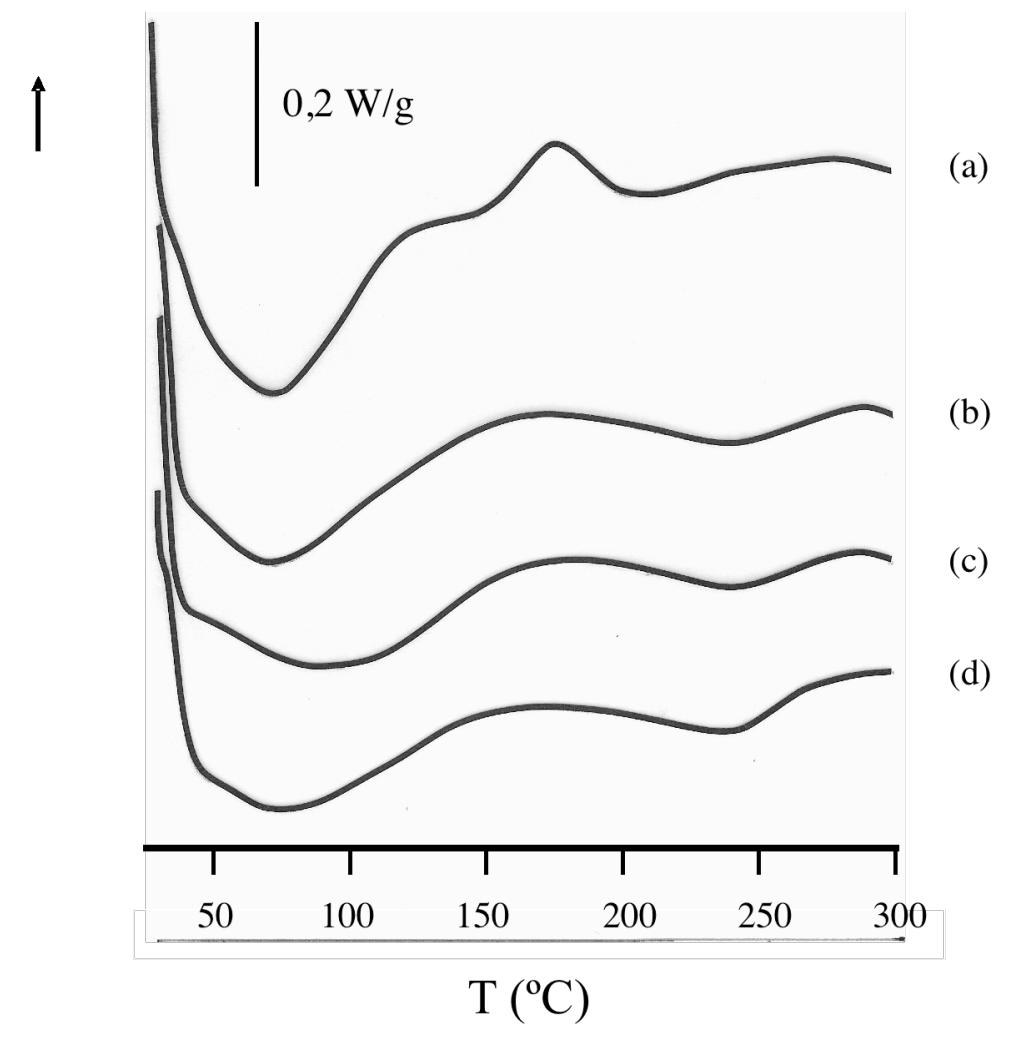

Figure 2 - DSC thermograms: (a) U(600), (b) n=100, (c) n=500 and (d) n=1000. 


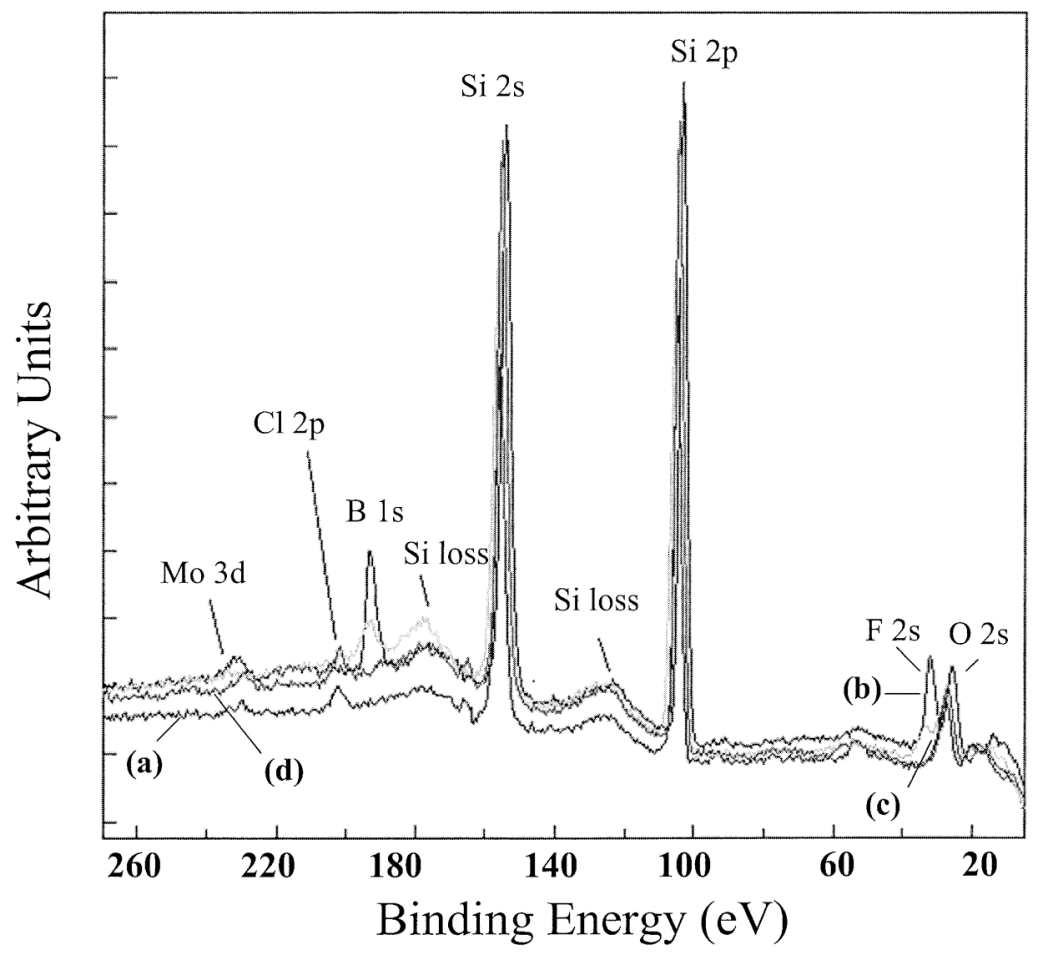

Figure 3 - XPS spectra: (a) U(600), (b) n=100, (c) n=500 and (d) n=1000. 


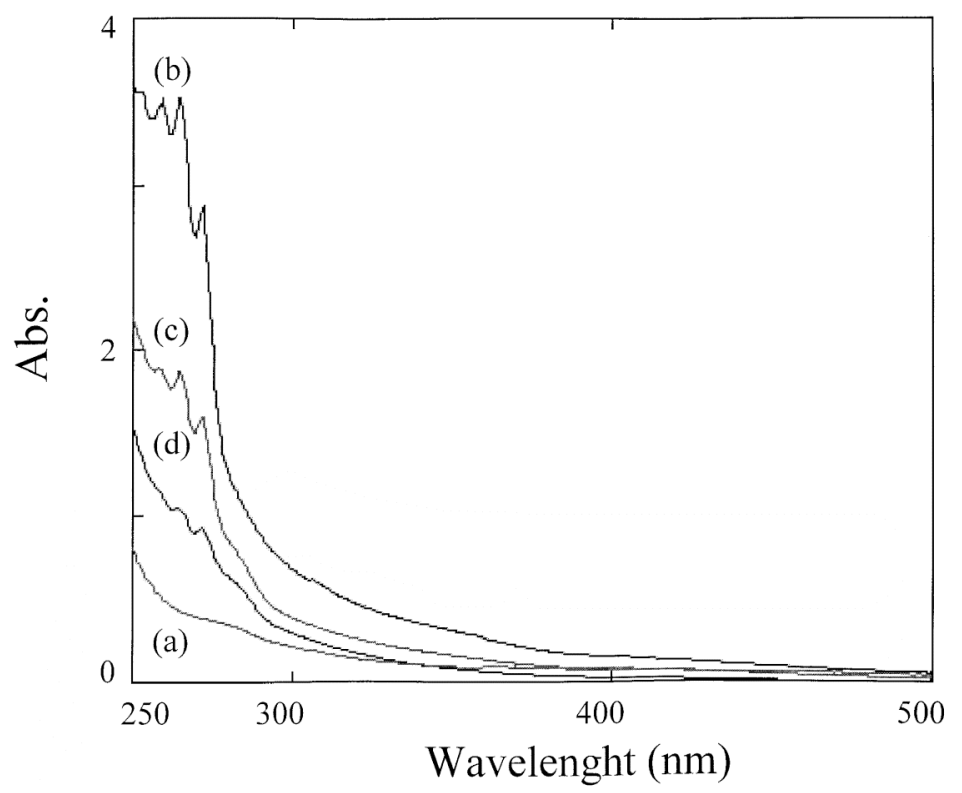

Figure 4 - UV/vis spectra: (a) U(600), (b) $n=100$, (c) $n=500$ and (d) $n=1000$. 